\title{
The Effects of Romanian Legislation in the Case of European Funding in the Period 2014-2020
}

\author{
Steluta Radu, ${ }^{1, *}$ \\ ${ }^{1}$ University of Life Sciences Ion Ionescu de la Brad Iasi 1 \\ *Corresponding author. Email: stelaradu2010@yahoo.com
}

\begin{abstract}
The aim of the article is to analyse comparatively the regulations of the European Union those of Romanian legislation, as well as to present some aspects registered at the the implementation of the operational programs between 2014-2020. The objectives of the research were: the legal and financial impact of the European Social Fund on Romania, by highlighting laws, orders, decisions, instruments, notifications, contracts and additional acts, physical and electronic tools used to monitor and evaluate indicators of result; the evolution of the financing dynamics (registered result indicators) of Romania within the seven priority axes financed in the period 2014-2020. The study of legal sociology highlighted the current state of Romania regarding European funding, highlighting the harmonization of national legislation with European and the legislative impact on the final beneficiaries of European funding.
\end{abstract}

Keywords: European's, Absorption, Funds.

\section{INTRODUCTION}

The National Strategies Research Financial is implemented through the Operational Programs within the "Convergence" and "European Territorial Cooperation" Objectives. [5] The Operational Programs developed by Romania or in the elaboration of which it collaborates with other member states and non-EU members, as well as the institutions responsible for managing these programs are[5]: Operational Program human capital - POCU 2014, Operational Program Disadvantaged People - POAD 2014, Operational Program Competitiveness Operational Program Large Infrastructure POIM 2014, Operational Program Technical Assistance - OPTA 2014, Operational Program Regional Development ROP 2014, Operational Program Administrative Capacity POCA 2014, Operational Program Agriculture and Fisheries PNDR 2014, Operational Program Cooperation 2014.[6] Identifying the programmatic legal documents for the period 2014-2020 of European financing, with the estimation of the legal norms that can be improved by legislation compared to the previous financial year 2007-2013, the proposal of legal and economic-financial innovation mechanisms are aspects that can bring numerous advantages in future Community funding.[4]Currently, European funding registers particular situations in all European states, and in Romania, as a result of the Romanian legislative framework which has atypical situations due to different forms of organization of Romanian state institutions. This is also validated by the fact that at least 4 of the 7 financing axes have launched projects for institutions or territorial administrative units coordinated by the Romanian government, so that the projects can be financed more easily and have more beneficiaries, as members in the target group. This technique was motivated by the need for a better absorption of European funds.[4]

\section{RESEARCH METHOD}

In this experiments, the applied quantitative research method was used to: systematize European and national legislation on European funds, store legislative records, identify judicial practice decisions (of previous T145 courts), store and systematize legal scientific information necessary for writing the paper. The applied research methods used in this study are related to the application of a questionnaire aimed at conducting an opinion poll in conducting a sociological legal survey:

experimental sampling method, in the case of SMEs; [2]The method used in the research was the comparative analysis between the legislation developed by the European Parliament and the Council of Europe and other European Union Member States, including Romania, related to European funding;[3]-Comparative 
analysis of some legal cases regarding litigations in case of flat-rate financial corrections applied to Romania regarding the adaptation of national legal norms to European legal norms management of European funds; Innovation of a judicial control mechanism through the elaboration and systematization of legislation, legislative records, records of judicial decisions in the field of European funds management (precedents), storage and systematization of legal information related to the management of European funds in all Member States European Union etc. Monitoring the level of knowledge of national and European legal norms, has used the financial instruments for European financing in Romania. In financial years 2007-2013 and 2014-2020 the legal person having the quality of beneficiary is not to blame for errors, but the character of legislative ambiguity, as well as the lack of legal verification tools parallel to the financial accounting verification, performed to validated reimbursement/ payment requests. Thus, the innovation of the legislative mechanism of legal verification must include levers that can correlate the rules of European law in the European Union Directives, with the rules of domestic law, especially in the next funding period 2014-2020. The use of instruments that harmonize the rules of European law with the rules of international law in the management of European funds aims at: amicably resolving legal disputes for the most part, reducing disputes in the case of European financing contracts, eliminating judicial errors of legislative interpretation for newly created and highly customized cases, due to their complexity, achieving a full concordance between the rules of European law with the rules of domestic law, thus avoiding disputes to the EU Tribunal. The legal model's monitoring mechanism will include a global system of verification and control of legal norms, provided by the regulations of the European Union in order to obtain sufficient assurance on the efficiency of risk management error regarding the legality and regularity of financing, having essentially the following steps [1]: The second stage is the establishment of a mandatory legal advice administrative structure in the eight regions, based on the establishment of legal monitoring agencies and an authority in charge of their authorization, the second stage is the innovation and development of detailed control systems and sanctions to be applied by the monitoring agencies, the third step is to carry out ex ante controls by independent certification bodies designated by the Member States in accordance to Regulation (EC) No 1234/2007.[8] Regulation no. $1290 / 2005$ of the Council on the administrator of European funds, applied the principle ratione temporis at the time of carrying out the controls to the Romanian conciliation body; being the fourth step in closing the conformity clearance procedure. [7]

\section{FIGURES AND TABLES}

Survey on the investigation of trends related to the impact of the financing of project in Romania. The survey was conducted on a sample of 1235 respondents with the aim of scientific research of the elements of legal sociology in the case of European funding.

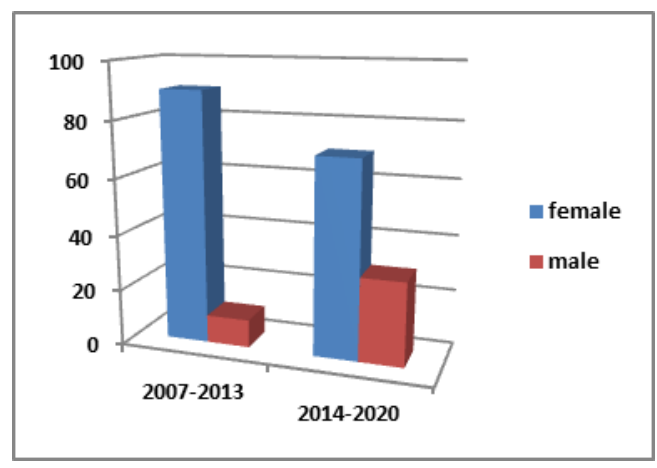

Figure 1 The dynamics of the respondents' gender affiliation in the implementation of European projects.

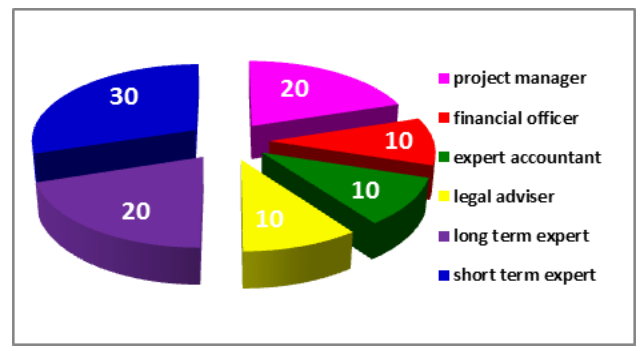

Figure 2 The quality of respondents in the european projects.

The sample of respondents was by $70-90 \%$ female and $10-30 \%$ male. Percentage of $20 \%$ increased at the male.(fig.1) The sample of respondents are the following distribution: shares between $10-20 \%$ held the positions of project manager, legal advisor, financial auditor, accounting expert; $10 \%$ were engaged in administrative, financial, accounting and procurement activities; $20 \%$ of them had long and short term expert positions or were part of the target group. (fig. 2) $50 \%$ of the respondents consider that they had financial advantages because they participated in the implementation of European projects, 20\% received initial training and advanced training, and $10 \%$ participated in current professional training. (fig. 3) Most $40 \%$, were involved in several projects, $20 \%$ of them participated in 1, 2 or 3 projects (Fig. 4). 


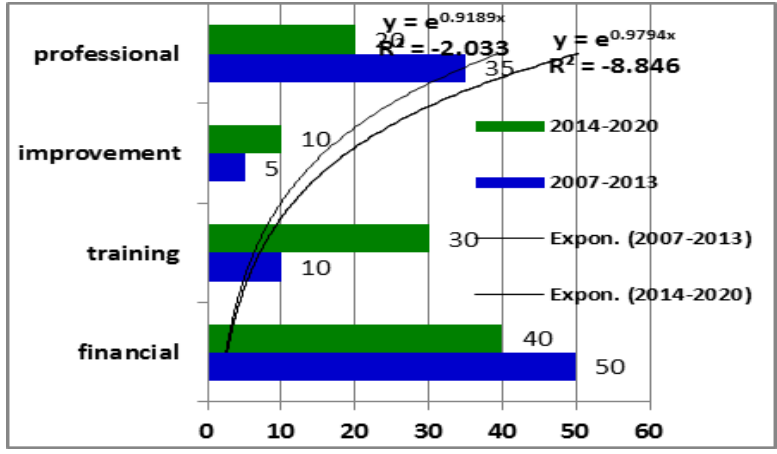

Figure 3 Distribution of benefits resulting from participation in European projects.

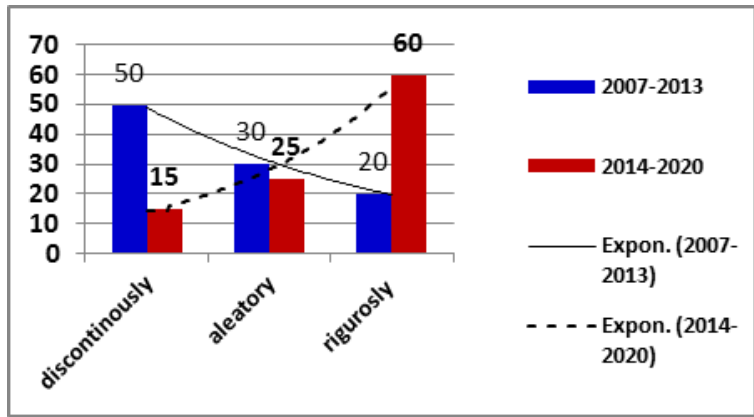

Figure 4 Estimating the application of legislative norms.

In conclusion, European funding brought material and professional benefits to the participants, especially in the case of female membership. Following other elements of legal sociology, which were highlighted during the implementation of the projects, we found that: $60 \%$ of the respondents were informed through organized training; $20 \%$ of them through the management team or individual-self-taught; $10 \%$ by other means. (fig.5) Figures 5, 6 show that $50 \%$ of the survey participants consider that the application of legal regulations regarding European funding in the period 2007-2013 was discontinuous:30\% say it was a random activity, $20 \%$ appreciate that the application was rigorous.

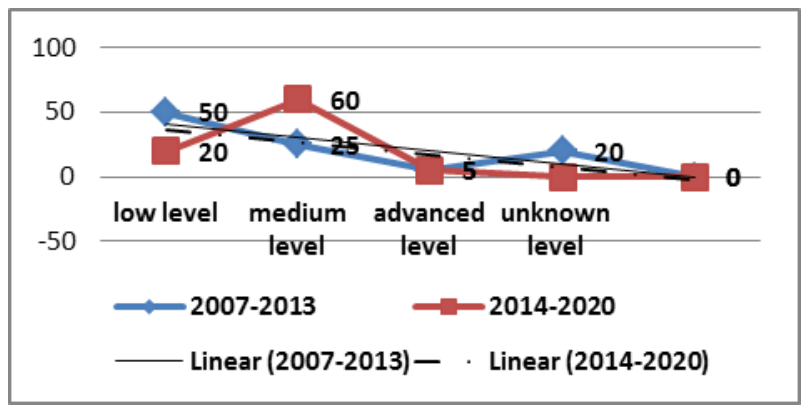

Figure 5 Dynamics of the knowing, understanding the national/European legal norms at the implementing.

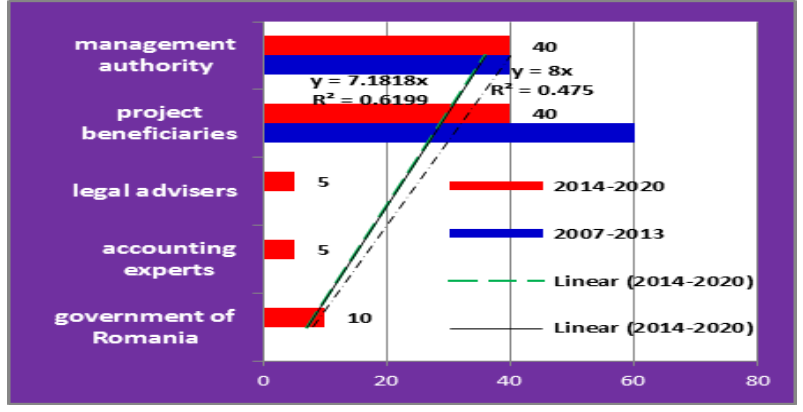

Figure 6 Dynamics of efficient coordination of European projects.

Appreciate how the legal regulations regarding the European financing in Romania were applied. Indicate your level of knowledge of national / European legal norms at the beginning of project implementation. Regarding the level of knowledge and understanding of national / European legal rules: a.in the period 2007$2013,60 \%$ of the respondents consider that they had a low level, b. $20 \%$ did not know at all the European legislation, which is an element that induces a high level of risk regarding the irregularities, $20 \%$ had an average level of knowledge, $10 \%$ an advanced level (figure 5) We notice that only $10 \%$ of them could be rigorous in enforcing the legislation, the rest had gaps that could generate non-compliance and risks. In the period 2014$202050 \%$ had a high level, $25 \%$ a medium level, and $5 \%$ low level. Thus, the link that is established between the correlations of values of the recorded variables is a statistical correlation of an experimental research. In this case it is observed that the point does not align perfectly on a straight line, but they tend to group around a certain straight line. It results that between the variables time periods and the level of knowledge of the national / European legislation we are dealing with a weak positive correlation for the period 2007-2013.

For the period 2014-2020 the points are not perfectly grouped around a straight line, thus having a lower performance, consequently a higher negative correlation. When survey participants were asked about "Who should legally and financially coordinate the implementation of European projects", they answered as follows: 2007-2013-60\% of them believed that the managing authority, while $40 \%$ believed that the beneficiary of the project. Between 2014-2020, $40 \%$ of them responded the same, the managing authority and the beneficiaries of the projects, while $10 \%$ appreciated that the Romanian government and only 5\% the legal advisers/ accounting experts. Regarding the assessments related to the legal coordination of EU projects, we also have a weak positive correlation, both for the period 2007-2013 and for the period 2014-2020. This is justified by random factors that occur during the implementation of European funding applications.(fig 6) Regarding the limits of national legislation compared to European ones, we can conclude as follows: between 
2007-2013 funding phase, $65 \%$ of respondents consider that we are dealing with ambiguity regarding national legislation; $20 \%$ talk about the complexity of the National legislation, and $10 \%$ about its lack of flexibility; $5 \%$ recall the lack of harmonization between national and European legislation, and the percentage is real as we have some weaknesses in this regard, the models and enforcement mechanisms are deficient.(fig 7) In $2014-202050 \%$ of the beneficiaries say that the legal norms are too complex, $30 \%$ consider that they are ambiguous.

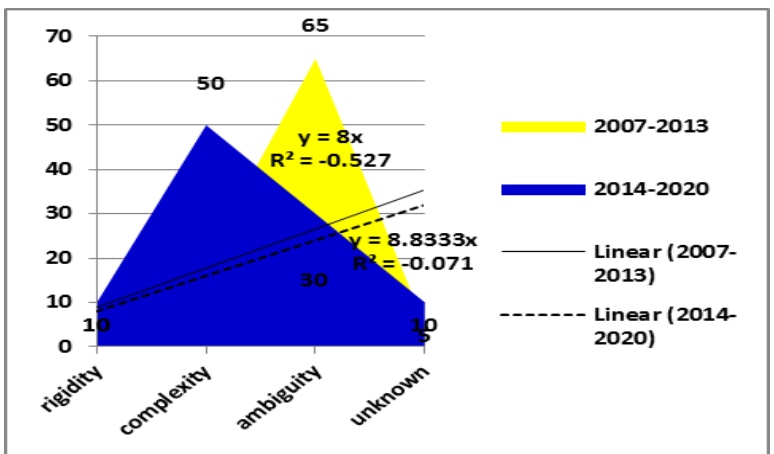

Figure 7 Estimation limits of european reglemetations.

The comparative analysis of national and European legislation found that the maximum amplitude in 2007-2013 was related to the ambiguity of the legislative framework, while in 2014-2020 the complexity of the legislative framework was a risk point reflected in the implementation of European projects. Therefore, the statistical correlation in the first period 20072013 and in the first period 2014-2020 is negative, the one in the first period being more accentuated.(fig.7).

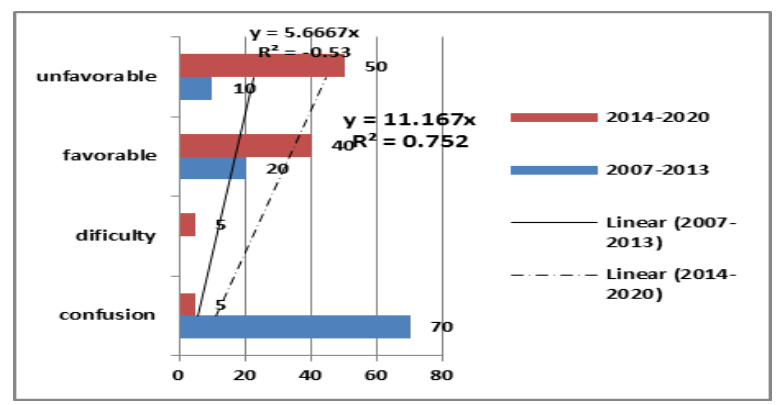

Figure 8 The level of influence of the legislative framework on the participants in the implementation of European projects.

Analysing aspects related to the overall legal / metalegal framework, we found that: a. for the period 2007$201370 \%$ of the respondents appreciated that it put them in difficulty, $20 \%$ tried a state of confusion, and $10 \%$ of them disadvantaged them; $b$. in the period 2014$2020,40 \%$ of respondents answered favourably, $50 \%$ unfavourably, and 5\% confusion, $5 \%$ difficult to understand. No subject considers that it would have been advantageous, from which we conclude that the inconsistency, the ambiguity gave uncertainty, as well as the possibility of those who implemented European projects to register risks of irregularities. Regarding the level of influence of the legal framework on the participants in the implementation. It is observed that the points tend to align around a straight line, where we are dealing with an average positive correlation for the period 2014-2020. On the other hand, in the period 2007-2013, the points do not group perfectly around a straight line, resulting in a lower performance and a negative correlation. (figure 8) Analysing the limits of the extrajudicial national regulations compared to the European ones, in the period 2007-2013, the participants answered that: a. some regulations were elaborated after the beginning of the implementation of the projects ( $40 \%$ of them); b.some regulations sometimes produced major negative mutations during implementation $(30 \%$ of subjects);c. other regulations were not clear, concise or were elaborated late after the implementation of the projects (30\% of the subjects). (fig.9) In the period 2014-2020 it is observed the introduction of norms in a percentage of $70 \%$ at the beginning of the implementation of financing errors, reducing to $25 \%$ the introduction of norms during the project and only $5 \%$ at its completion. From this it can be concluded that regarding the legislative framework in 2014-2020, it was less variable and did not produce unfavourable effects.

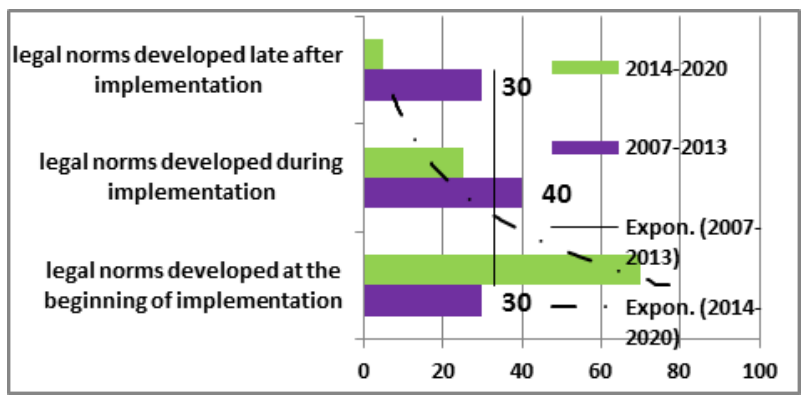

Figure 9 Estimation of national extrajudicial limits compared to European ones.

When assessing the answers related to the moment of application of the legal norms, we notice a much higher negative exponential statistical correlation in the period 2007-2013, compared to the period 20142020.(fig.9)The decrease of the impact of the application of the legal norms is justified by the elimination of the procedure of introducing the legal norms during their implementation.

\section{CONCLUSIONS}

1. The causes of the low level of trust that people have in European funding are related to the difficulties of implementing European-funded projects. It turns out 
that only $40 \%$ of respondents are fully satisfied with the implementation of European projects. The measures were taken during the implementation and therefore had an important economic substratum for development. 2 . If we compare the financial and economic activity of a small and medium business in Romania in 24 month in which they carried out projects with European financing we will find that the activity of Romanian companies has increased a lot compared to traditional companies without Europeans funds. The economic activity increased at the same entrepreneur, too. 3. An even more dramatic consequence is the fact that the work team of the companies cannot carry out the project activities on time, without encountering difficulties in terms of procurement, financial-accounting and other such objectives because: it is not formed to make documentation for 200,000 lei per month, they do not have the skills and dexterity to adapt to work on IT applications, the rigor in carrying out the acquisition activity.4. Due to the lack of specialization, sometimes the project management is not efficient, regardless of the field of activity, so it is inevitable not to reach the initially proposed targets, which are often ambitious compared to the context of the projects.

RECOMMENDATIONS. Thus, for the next financial years, national strategies, better defined legal and extra-legal rules, structured and organized in a legal manner correlated with the system of economic rules are needed for better efficiency. From the experience of the previous financial years 2000-2006, 2007-2013, until now, we notice that Romania does not reach a maximum level of absorption of the allocated European funds. The causes are frequently highlighted, but the subsequent measures are missing, which optimize and streamline the activity, in order to obtain a positive result.

\section{AUTHORS' CONTRIBUTIONS}

"Steluța Radu CONTRIBUTIONS": was written this article, was involved in the survey of this research.

\section{ACKNOWLEDGMENTS}

This article was written with public information and sociological experiments in Romania. There is no conflict of interest.

\section{REFERENCES}

[1] V. Hanga, The Decision Support Computer, Legal Studies and Research, 1, 1989, pp. 73-75; idem, Computer Aided Legal Education, S.C.J. 2.1988;

[2] T. Paraschiv, I. Stoi, M. Bota, Legal Informatics, 1, Concepts and operation, Ed.Augusta, Timisoara, 1998;

[3] www.methods of juridical research.ro
[4] European framework governing Member States' funding for 2014-2020;

[5] CSNR National Strategic Reference Framework 2007-2013

[6] Operational Programs in the period 2014-2020

[7] Regulation (EU) No 182/2011.

[8] Regulation EU 1306/2013 of the European Parliament and of the Council of 17 December 2013. 